Provided for non-commercial research and education use. Not for reproduction, distribution or commercial use.

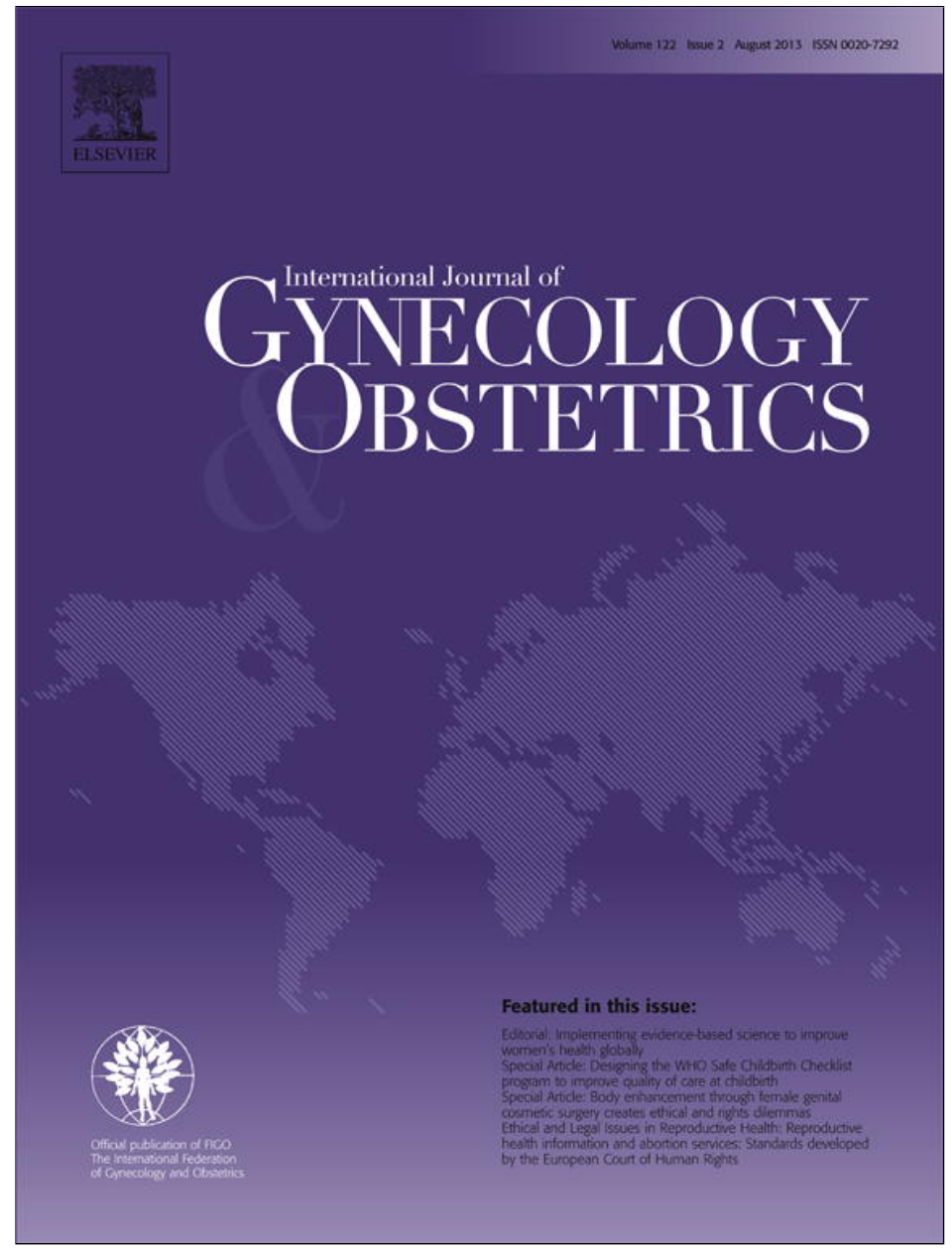

This article appeared in a journal published by Elsevier. The attached copy is furnished to the author for internal non-commercial research and education use, including for instruction at the authors institution and sharing with colleagues.

Other uses, including reproduction and distribution, or selling or licensing copies, or posting to personal, institutional or third party websites are prohibited.

In most cases authors are permitted to post their version of the article (e.g. in Word or Tex form) to their personal website or institutional repository. Authors requiring further information regarding Elsevier's archiving and manuscript policies are encouraged to visit:

http://www.elsevier.com/authorsrights 


\title{
Pregnancy outcome after loop electrosurgical excision procedure for cervical intraepithelial neoplasia
}

\author{
Antonio Frega ${ }^{\mathrm{a}, *}$, Francesco Sesti ${ }^{\mathrm{b}}$, Luana De Sanctis ${ }^{\mathrm{a}}$, Arianna Pacchiarotti ${ }^{\mathrm{a}}$, Sergio Votano ${ }^{\mathrm{c}}$, \\ Alberto Biamonti ${ }^{\mathrm{d}}$, Francesco Sopracordevole ${ }^{\mathrm{e}}$, Paolo Scirpa ${ }^{\mathrm{f}}$, Angelica Catalano ${ }^{\mathrm{a}}$, \\ Donatella Caserta ${ }^{\text {a }}$, Marco Gentile ${ }^{a}$, Mauro Schimberni ${ }^{a}$, Massimo Moscarini ${ }^{\text {a }}$ \\ a Department of Gynecological, Obstetric and Urological Sciences, Sant'Andrea Hospital, Sapienza University of Rome, Rome, Italy \\ b Section of Gynecology, Academic Department of Biomedicine and Prevention and Clinical Department of Surgery, Tor Vergata University Hospital, Rome, Italy \\ c Department of Obstetrics and Gynaecology, San Carlo Hospital-IDI IRCCS, Rome, Italy \\ d Department of Obstetrics and Gynaecology, Cristo Re Hospital, Rome, Italy \\ e National Cancer Institute, Department of Gynaecologic Oncology, Aviano, Italy \\ ${ }^{\mathrm{f}}$ Department of Gynaecology and Obstetrics, Catholic University, Rome, Italy
}

\section{A R T I C L E I N F O}

\section{Article history:}

Received 25 November 2012

Received in revised form 4 March 2013

Accepted 19 April 2013

\section{Keywords:}

Cervical length

Cervical intraepithelial neoplasia

Cone size

Loop electrosurgical excision procedure

Nulliparous

Obstetric outcomes

Preterm delivery

Spontaneous abortion

\begin{abstract}
A B S T R A C T
Objective: To determine pregnancy outcomes among women who underwent loop electrosurgical excision procedure (LEEP). Methods: In a case-control study in Italy, 475 pregnant women who underwent LEEP and 441 untreated pregnant women were enrolled between January 2003 and January 2007. Outcome measures were spontaneous abortion, preterm delivery, and at-term delivery rates. Continuous and discrete variables were analyzed via $t, \chi^{2}$, and Fisher exact tests. Groups were compared by analysis of variance and Tukey HSD test. Results: The spontaneous abortion rate was $14.5 \%$ and $14.1 \%$ in the LEEP and untreated groups, respectively. The preterm delivery rate was $6.4 \%$ and $5.0 \%$ in the LEEP and untreated groups, respectively. The number of women with a cervical length of less than $30 \mathrm{~mm}$ was higher in the LEEP group, but this did not influence preterm delivery rate (odds ratio [OR], 1.01; 95\% confidence interval [CI], 0.53-1.95). Among women with a cervical length of less than $15 \mathrm{~mm}$, those treated with a wider removal of cervical tissue showed increased risk of preterm delivery (OR, 5.31; 95\% CI, 1.01-28.07). Conclusion: The preterm delivery rate was not higher among women who underwent LEEP than among untreated women. Preterm delivery was associated with cone size and cervical length in the second trimester.
\end{abstract}

(c) 2013 International Federation of Gynecology and Obstetrics. Published by Elsevier Ireland Ltd. All rights reserved.

\section{Introduction}

In the past 30 years, the incidence of invasive cervical cancer has decreased markedly owing to far-reaching screening programs that have led to the early diagnosis and treatment of cervical intraepithelial neoplasia (CIN) among asymptomatic women [1]. Several techniques have been used in the treatment of pre-invasive lesions, such as cold-knife conization, laser ablation, laser conization, and loop electrosurgical excision procedure (LEEP) [2]. The last technique has become the standard treatment for women affected by cervical precancer lesions, owing to its low rate of morbidity, the possibility of following out the margins of the excised tissue with a precise histologic diagnosis, and the ability to combine diagnosis and therapy in an outpatient clinic [3].

\footnotetext{
* Corresponding author at: Department of Gynecological, Obstetric and Urological Sciences, Sant'Andrea Hospital, Sapienza University of Rome, Via di Grottarossa 1035-1039, 00189 Rome, Italy. Tel.: + 39 330885977; fax: + 390692932259.

E-mail address: a.frega@tin.it (A. Frega).
}

The incidence of CIN generally peaks among women aged approximately 30 years, during their reproductive age; consequently, any possible effect of its treatment on future childbearing should be considered carefully [4]. An early report showed that there is an association between cold-knife conization and adverse obstetric outcomes, including preterm delivery [5]. Subsequently, several systematic reviews and large retrospective studies have reported that women who have undergone LEEP have a 1.7-3.7-fold increased risk of preterm delivery, low birth weight, and premature rupture of the membrane compared with untreated women [6-13].

By contrast, few data on the fertility and reproductive performance of women treated by LEEP are available [14], although Jakobsson et al. [15] reported that there is not a strong association between cervical conization or ablation and subfertility. Two retrospective studies based on data from hospital registries and meta-analysis have been carried out $[16,17]$. To our knowledge, however, no prospective studies with appropriate untreated controls have analyzed the pregnancy outcome of women who have undergone LEEP.

Among women with a higher risk of preterm delivery or midtrimester loss, transvaginal cervical sonography is generally used in 
the second trimester of pregnancy to evaluate cervical length. Some authors consider that a cervical shortening discovered before gestational week 24 is equivalent to cervical insufficiency and is a risk factor for preterm delivery [18-20]. Among women previously treated with LEEP, cervical length is often monitored during the second trimester, but there is no preset reference value for this group of women. It is uncertain whether a precedent excision treatment leads to a permanent shortening of the cervix [19].

The aim of the present study was to estimate the effects of LEEP on pregnancy outcome among nulliparous women who had previously been treated for CIN.

\section{Materials and methods}

The present case-control study was conducted in university teaching hospitals and country hospitals across Italy from January 1 , 2003 , to January 31,2007 , to compare pregnancy outcomes between women who had previously undergone LEEP and untreated control women. The study was reviewed and approved by the Institutional Review Board (Prot.CE 131/12). All of the women who had been previously treated with LEEP and all study participants provided informed written consent.

The case inclusion criteria were age 42 years or younger, 1 previous treatment of CIN 2-3 with LEEP, no relapse of CIN for at least 12 months after LEEP, spontaneous pregnancy, white ethnicity, and nulliparity. The exclusion criteria were twin pregnancies, a history of repeated cervical excisional or ablative treatments, any major disease (e.g. cardiovascular disease, diabetes, HIV infection, or hypertension), and alcohol, smoke or substance abuse.

The control inclusion criteria were age 42 years or younger, white ethnicity, nulliparity, spontaneous pregnancy, and no previous treatment for CIN. The exclusion criteria were twin pregnancies, any major disease (e.g. cardiovascular disease, diabetes, HIV infection, or hypertension), and alcohol, smoke or substance abuse. Control women were referred for a gynecologic visit to the same centers where the LEEP patients had been recruited.

Each LEEP was performed by a single surgeon in each study center using the same technique. Cone size was based on the loop dimension: small, less than or equal to $10 \times 10 \mathrm{~mm}$; middle-sized, $15 \times 12 \mathrm{~mm}$; large, $20 \times 15 \mathrm{~mm}$. Pregnant women who had undergone LEEP were managed throughout pregnancy by periodic clinical examinations and ultrasound scans until delivery. Gestational age was determined by dating the ultrasound scan in the first trimester. At 22-24 gestational weeks, all women underwent a transvaginal ultrasound scan to measure the cervical length. In brief, cervical length was assessed in the sagittal plane with the bladder empty; the internal and external cervical os were visualized together. Three measurements were obtained, and the shortest one was recorded as the cervical length. The control group of untreated pregnant women was followed-up during the whole pregnancy in the same way as the treated group.

The primary outcome measure was the comparison of gestational age at birth (at-term delivery, $\geq 37$ weeks; preterm delivery, 24-36 weeks; spontaneous abortion, $\leq 24$ weeks) between LEEP-treated (case) and untreated (control) pregnant women. Any additional factors that might have been related to prematurity were recorded.

Statistical analysis was carried out via SPSS version 10 (IBM, Armonk, NY, USA). Continuous outcome variables were analyzed by Student $t$ test. Discrete variables were analyzed by $\chi^{2}$ test or Fisher exact test. The 2 groups were compared via a 1 -way analysis of variance (ANOVA), followed by Tukey HSD for post-hoc comparison of the mean values. A $P$ value less than 0.05 was considered statistically significant.

\section{Results}

During the study period, 1463 consecutive women underwent LEEP for CIN 2-3 and were examined for study eligibility. Of these,
134 refused to participate; as a result, data from 1329 nulliparous women who had previously undergone LEEP were reviewed in the study. Among these women, no intraoperative complications occurred, and no early postoperative complications requiring readmission, blood transfusion, or repeat surgery were observed after the procedure.

Subsequently, 598 of the LEEP-treated women tried to become pregnant 1 year after LEEP. In total, 493 (82.4\%) succeeded and became pregnant. Of these, 18 women (3.7\%) were lost to follow-up, and thus 475 women comprised the case study population (Fig. 1).

For the control group, 462 white, nulliparous women aged 42 years or younger who had become pregnant spontaneously and had not previously been treated for CIN were enrolled in the study. Of these, 21 women lost to follow-up, and thus 441 control women comprised the control study population (Fig. 2).

The mean age of the LEEP-treated pregnant women was $30.8 \pm$ 3.9 years (range, $18-35$ years), whereas the mean age of the untreated pregnant women was $31.9 \pm 4.0$ years (range, 20-36 years) (Table 1 ).

Among the 475 LEEP-treated women, 69 (14.5\%) experienced spontaneous abortion at 24 weeks or less, $26(6.4 \%)$ had preterm delivery at 24-36 weeks, and 380 (93.6\%) had at-term delivery (Fig. 1). Among the 441 untreated women, 62 (14.1\%) experienced spontaneous abortion at 24 weeks or less, 19 (5.0\%) had preterm delivery at 24-36 weeks, and 360 (95.0\%) had at-term delivery (Fig. 2). The difference in preterm delivery rate between the 2 groups was not significant (odds ratio [OR], 1.30; 95\% confidence interval [CI], $0.71-2.38 ; P=0.40$ ) (Table 2).

The cervical length at 22-24 gestational weeks was assessed by ultrasound. The mean cervical length according to cone size in the LEEP group is given in Table 3. Among women in the untreated group, the mean cervical length was $3.7 \pm 0.7 \mathrm{~cm}$.

In total, 142 (34.9\%) women in the LEEP group had a cervical length of less than $30 \mathrm{~mm}$, compared with 105 women $(27.7 \%)$ in the untreated group (OR, 1.40; 95\% CI, 1.04-1.90; $P=0.03$ ). All preterm deliveries were observed among women with a cervical length of less than $30 \mathrm{~mm}$. Although the number of women with a cervical length of less than $30 \mathrm{~mm}$ was greater in the treated group, this did not influence the preterm delivery rate $(\mathrm{OR}, 1.01 ; 95 \% \mathrm{CI}, 0.53-1.95$; $P=0.97$ ). Among pregnant women with a cervical length of less than $15 \mathrm{~mm}$, those who had been treated with a wider removal of cervical tissue showed an increased risk for preterm delivery compared with untreated women (OR, 5.31; 95\% CI, 1.01-28.07; $P=0.04$ ) (Table 4).

Preterm delivery was significantly associated with cone size. Among the 85 women who had undergone LEEP with a large cone size, $10(11.8 \%)$ had preterm delivery, and $75(88.2 \%)$ delivered at term (OR, 2.54; 95\% CI, 1.11-5.83; $P=0.02$ ) (Table 5).

\section{Discussion}

Cervical intraepithelial neoplasia is common among women of reproductive age, and LEEP is the most frequently performed modality of treatment for CIN. Women who have had a previous cone biopsy have a significant risk of complications such as pre-term labor, low newborn weight, and perinatal mortality. It is possible that LEEP might increase these complications and the risk of adverse pregnancy outcomes, but previous data are conflicting. The pathogenic mechanism of preterm delivery after cervical surgery is little understood.

It has been hypothesized that premature rupture of membranes and preterm delivery might be caused by a decline in mechanical support from the cervix, a mutation of the immunologic defense, or a distortion in cervicovaginal bacterial flora [19]. After an excisional procedure, the cervix heals by regeneration of ectocervical components, but generation of endocervical glands-which are responsible for cervical mucus production-is limited; therefore, a reduction in the production of cervical mucus may lead to a predisposition to upper tract infection and decreased immune function [21]. 


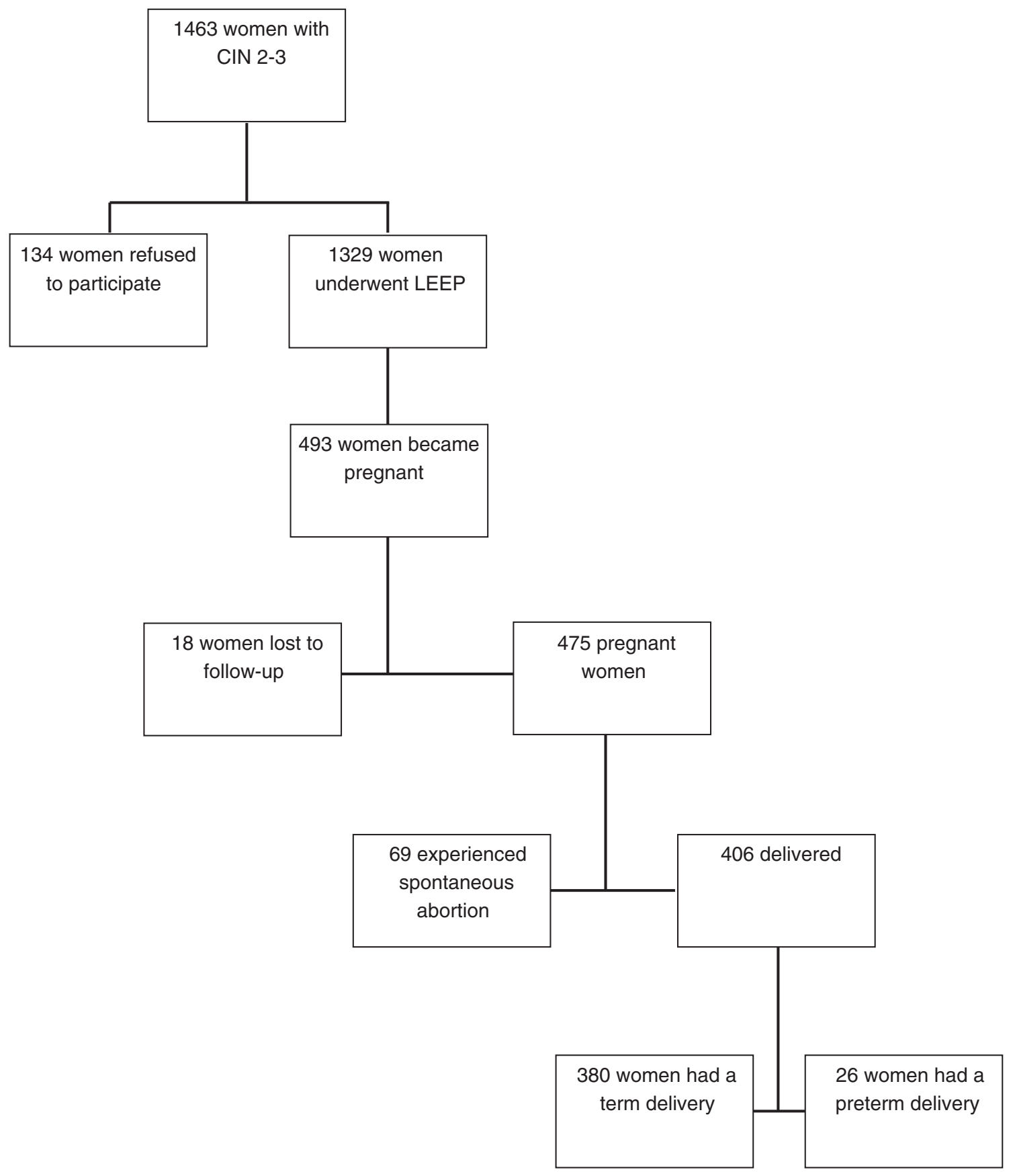

Fig. 1. Flow of LEEP-treated patients through the study.

Alternatively, the risk of developing cervical dysplasia might be related to other demographic, behavioral, or infectious factors, and not to the surgery itself [19]. It has been recently reported that women affected by CIN show increased mortality and a higher frequency of health problems compared with the general population. This may be due to their life style and socioeconomic status. Consequently, their increased risk of preterm delivery might be related to these factors [22].

Different studies have tried to elucidate the reasons for preterm delivery after conization. Sadler et al. [7] demonstrated a correlation between the height of the removed cone and the risk of preterm delivery. It has been suggested that the function of the cervix is more likely to be affected when more tissue is removed [7,17]. A meta-analysis conducted by Kyrgiou et al. [9] found that the risk of preterm delivery increased when more than $10 \mathrm{~mm}$ of cervical tissue was removed. Obviously, a correct and precocious diagnosis of pre-cancerous lesions can lead to a reduction of the amount of tissue excised: it has been clearly demonstrated that the quantity of tissue excised influences the obstetric outcomes [9,17].

The present study found that women who had previously been treated with LEEP did not show significant differences compared with the untreated women in terms of spontaneous abortion. However, a higher preterm delivery rate was observed among women who had previously undergone LEEP than among untreated women, although the difference did not reach significance probably because of the limited number of events. Furthermore, no preterm delivery before 32 weeks was observed.

Recent studies have been based on hospital or regional registries with large numbers of women who delivered after they had previously undergone LEEP. These retrospective studies show a 2.07- to 2.61-fold 


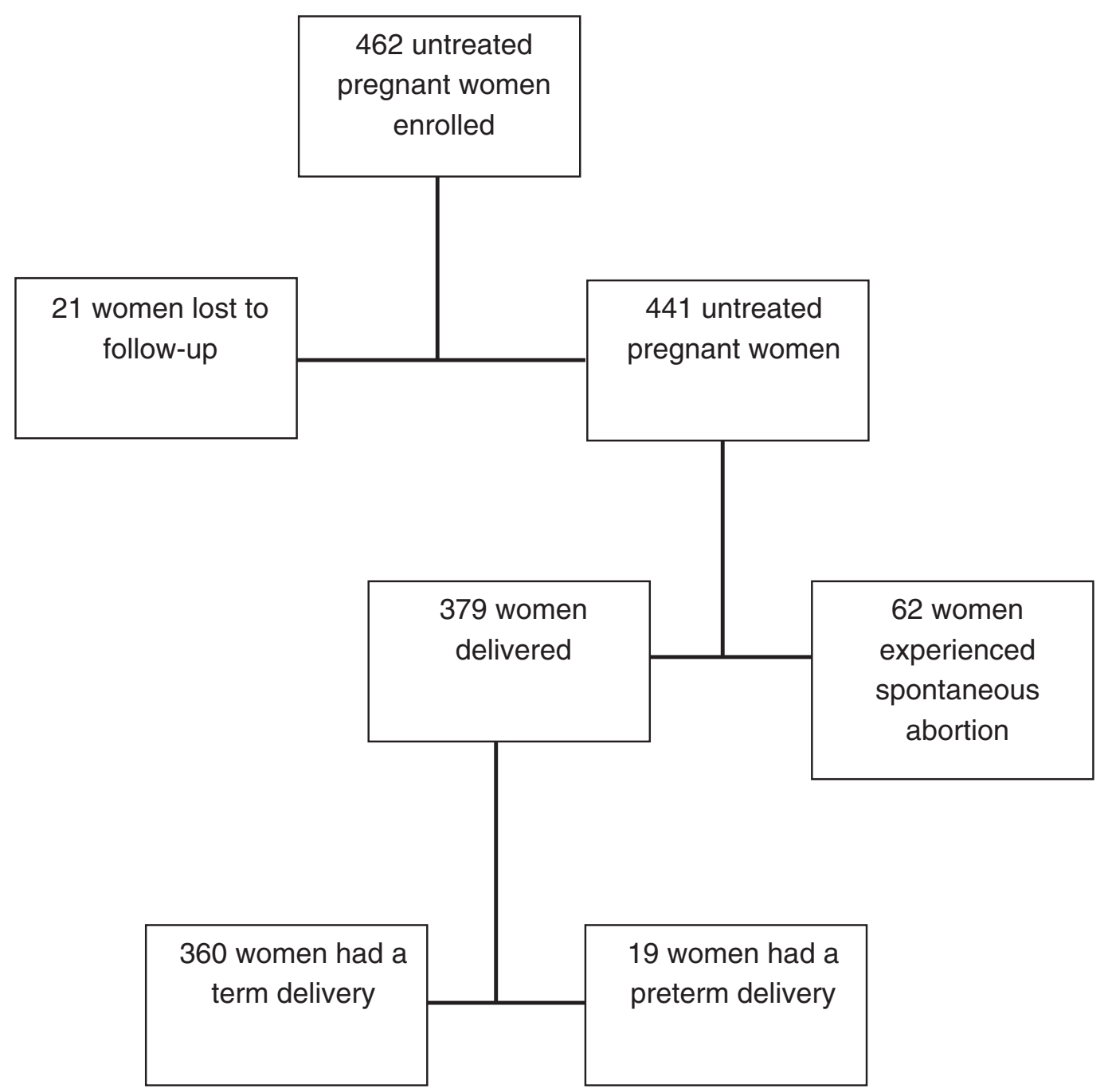

Fig. 2. Flow of untreated patients through the study.

increased risk of preterm delivery for LEEP-treated women $[9,10]$. Earlier papers have reported conflicting results. For example, Sadler et al. [7] reported no increased risk of preterm delivery, whereas Samson et al. [8] reported a 3.50-fold increased risk. In addition, meta-analysis reviews have shown a 1.7 -fold increased risk of preterm delivery for

Table 1

Characteristics of the study population. ${ }^{\text {a }}$

\begin{tabular}{lll}
\hline Characteristics & $\begin{array}{l}\text { LEEP group } \\
(\mathrm{n}=475)\end{array}$ & $\begin{array}{l}\text { Untreated group } \\
(\mathrm{n}=441)\end{array}$ \\
\hline Age, $\mathrm{y}$ & $30.8 \pm 3.9(18-35)$ & $31.9 \pm 4.0(20-36)$ \\
Nulliparous & 475 & 441 \\
White & 475 & 441 \\
\hline
\end{tabular}

a Values are given as mean \pm SD (range) or number.

Table 2

Pregnancy outcome among women treated with LEEP and untreated women. ${ }^{\mathrm{a}}$

\begin{tabular}{lccc}
\hline Clinical parameters & $\begin{array}{c}\text { LEEP group } \\
(\mathrm{n}=475)\end{array}$ & $\begin{array}{l}\text { Untreated group } \\
(\mathrm{n}=441)\end{array}$ & $P$ value \\
\hline Spontaneous abortion ( $\leq 24$ weeks $)$ & $69(14.5)$ & $62(14.1)$ & 0.84 \\
Preterm delivery (24-36 weeks) & $26(6.4)$ & $19(5.0)$ & 0.40 \\
Term delivery $(\geq 37$ weeks) & $380(93.6)$ & $360(9.5)$ & 0.40 \\
\hline
\end{tabular}

${ }^{a}$ Values are given as number (percentage) unless stated otherwise.
LEEP-treated women [9]. Recently, Castanon et al. [23] found that the risk of preterm delivery among women treated with large loop excision is lower than that reported in many other studies.

In the present study, the preterm delivery rate was $6.4 \%$ among women who had previously been treated with LEEP, whereas it

Table 3

Cervical length at 22-24 gestational weeks among women treated with LEEP.

\begin{tabular}{ll}
\hline Cone size & Cervical length, $\mathrm{cm}^{\mathrm{a}}$ \\
\hline Small & $3.5 \pm 0.46$ \\
Medium & $3.3 \pm 0.56$ \\
Large & $2.6 \pm 0.62$ \\
\hline
\end{tabular}

a Values are given as mean \pm SD.

Table 4

Cervical length among women treated with LEEP and untreated women. ${ }^{a}$

\begin{tabular}{lccc}
\hline Clinical parameters & $\begin{array}{c}\text { LEEP group } \\
(\mathrm{n}=406)\end{array}$ & $\begin{array}{l}\text { Untreated } \\
\text { group } \\
(\mathrm{n}=379)\end{array}$ & $P$ value \\
\hline Cervical shortening $(<30 \mathrm{~mm})$ & $142(34.9)$ & $105(27.7)$ & 0.03 \\
$\begin{array}{l}\text { Preterm delivery with cervical shortening } \\
\text { Preterm delivery with cervical }\end{array}$ & $26(100)$ & $19(100)$ & 0.97 \\
$\quad$ shortening $(<15 \mathrm{~mm})$ & $10(38.5)$ & $2(10.5)$ & 0.04 \\
Term delivery with cervical shortening & $116(30.5)$ & $86(23.9)$ & 0.97 \\
\hline
\end{tabular}

${ }^{a}$ Values are given as number (percentage) unless stated otherwise. 
Table 5

Preterm delivery rate among women treated with LEEP. ${ }^{\text {a }}$

\begin{tabular}{llcl}
\hline $\begin{array}{l}\text { Cone } \\
\text { size }\end{array}$ & $\begin{array}{l}\text { Preterm delivery (24-36 weeks) } \\
(\mathrm{n}=26)\end{array}$ & $\begin{array}{l}\text { Term delivery ( } \geq 37 \text { weeks) } \\
(\mathrm{n}=380)\end{array}$ & $P$ value \\
\hline Small & $10(4.6)$ & $206(95.4)$ & 0.12 \\
Medium & $6(5.7)$ & $99(94.3)$ & 0.74 \\
Large & $10(11.8)$ & $75(88.2)$ & 0.02 \\
\hline
\end{tabular}

${ }^{a}$ Values are given as number (percentage) unless stated otherwise.

was 5.0\% among untreated women (OR, 1.30; 95\% Cl, 0.71-2.38; $P=0.40$ ). It should be noted that both groups had similar demographic characteristics (Table 1 ).

To identify a subset of women at higher risk for preterm delivery after LEEP, many potential risk factors have been investigated. For example, numerous studies have reported that excised cone size $[8,13]$, number of cervical excisions [8], cervical length at 22-24 weeks of gestation $[20,24]$, and the time interval between surgery and pregnancy [25] are factors that might increase the risk of preterm delivery among women who have previously undergone LEEP. Excision treatments of the transition zone depend on the nature and the extent of the disease. In the present study, the preterm delivery rate was associated with the amount of tissue excised during the procedure: $38.5 \%$ of women who had a preterm delivery had a large cone size, and $100 \%$ of them showed a shortening of cervical length $(<30 \mathrm{~mm})$ at $22-24$ gestational weeks. This latter factor seems to be the most reliable for identifying which women are at highest risk for preterm delivery and require a stricter follow-up: namely, women with a cervical length of less than $25 \mathrm{~mm}$ should be hospitalized, whereas those with a cervical length of $25-30 \mathrm{~mm}$ should undergo close transvaginal cervical sonography control.

In conclusion, the risk of preterm delivery among nulliparous women who have previously undergone LEEP seems to be associated with cone size and cervical shortening. Among young women desirous of childbearing, LEEP should be tailored to avoid overtreatment.

\section{Conflict of interest}

The authors have no conflicts of interest.

\section{References}

[1] Quinn M, Babb P, Jones J, Allen E. Effect of screening on incidence of and mortality from cancer of cervix in England: evaluation based on routinely collected statistics. BMJ 1999;318(7188):904-8.

[2] Prendiville W, Cullimore J, Norman S. Large loop excision of the transformation zone (LLETZ). A new method of management for women with cervical intraepithelial neoplasia. Br J Obstet Gynaecol 1989;96(9):1054-60.

[3] Wright Jr TC, Cox JT, Massad LS, Carlson J, Twiggs LB, Wilkinson EJ, et al. 2001 consensus guidelines for the management of women with cervical intraepithelial neoplasia. Am J Obstet Gynecol 2003;189(1):295-304.
[4] Herbert A, Smith JA. Cervical intraepithelial neoplasia grade III (CIN III) and invasive cervical carcinoma: the yawning gap revisited and the treatment of risk. Cytopathology 1999;10(3):161-70.

[5] Andía D, Mozo de Rosales F, Villasante A, Rivero B, Díez J, Pérez C. Pregnancy outcome in patients treated with cervical conization for cervical intraepithelial neoplasia. Int J Gynecol Obstet 2011;112(3):225-8.

[6] Khalid S, Dimitriou E, Conroy R, Paraskevaidis E, Kyrgiou M, Harrity C, et al. The thickness and volume of LLETZ specimens can predict the relative risk of pregnancy-related morbidity. BJOG 2012;119(6):685-91.

[7] Sadler L, Saftlas A, Wang W, Exeter M, Whittaker J, McCowan L. Treatment for cervical intraepithelial neoplasia and risk of preterm delivery. JAMA 2004;291(17): 2100-6.

[8] Samson SL, Bentley JR, Fahey TJ, McKay DJ, Gill GH. The effect of loop electrosurgical excision procedure on future pregnancy outcome. Obstet Gynecol 2005;105(2): 325-32.

[9] Kyrgiou M, Koliopoulos G, Martin-Hirsch P, Arbyn M, Prendiville W, Paraskevaidis E. Obstetric outcomes after conservative treatment for intraepithelial or early invasive cervical lesions: systematic review and meta-analysis. Lancet 2006;367(9509): 489-98.

[10] Arbyn M, Kyrgiou M, Simoens C, Raifu AO, Koliopoulos G, Martin-Hirsch P, et al Perinatal mortality and other severe adverse pregnancy outcomes associated with treatment of cervical intraepithelial neoplasia: meta-analysis. BMJ 2008;337: a1284.

[11] Jakobsson M, Gissler M, Sainio S, Paavonen J, Tapper AM. Preterm delivery after surgical treatment for cervical intraepithelial neoplasia. Obstet Gynecol 2007;109(2 Pt 1): 309-13.

[12] Noehr B, Jensen A, Frederiksen K, Tabor A, Kjaer SK. Loop electrosurgical excision of the cervix and subsequent risk for spontaneous preterm delivery: a populationbased study of singleton deliveries during a 9-year period. Am J Obstet Gynecol 2009;201(1):33.e1-6.

[13] Shanbhag S, Clark H, Timmaraju V, Bhattacharya S, Cruickshank M. Pregnancy outcome after treatment for cervical intraepithelial neoplasia. Obstet Gynecol 2009;114(4):727-35.

[14] Turlington WT, Wright BD, Powell JL. Impact of the loop electrosurgical excision procedure on future fertility. J Reprod Med 1996;41(11):815-8.

[15] Jakobsson M, Gissler M, Tiitinen A, Paavonen J, Tapper AM. Treatment for cervical intraepithelial neoplasia and subsequent IVF deliveries. Hum Reprod 2008;23(10): 2252-5.

[16] Werner CL, Lo JY, Heffernan T, Griffith WF, McIntire DD, Leveno KJ. Loop electrosurgical excision procedure and risk of preterm birth. Obstet Gynecol 2010;115(3): 605-8.

[17] Armarnik S, Sheiner E, Piura B, Meirovitz M, Zlotnik A, Levy A. Obstetric outcome following cervical conization. Arch Gynecol Obstet 2011;283(4):765-9.

[18] Berghella V, Roman A, Daskalakis C, Ness A, Baxter JK. Gestational age at cervical length measurement and incidence of preterm birth. Obstet Gynecol 2007;110(2 Pt 1):311-7.

[19] Fischer RL, Sveinbjornsson G, Hansen C. Cervical sonography in pregnant women with a prior cone biopsy or loop electrosurgical excision procedure. Ultrasound Obstet Gynecol 2010;36(5):613-7.

[20] Berghella V, Pereira L, Gariepy A, Simonazzi G. Prior cone biopsy: prediction of preterm birth by cervical ultrasound. Am J Obstet Gynecol 2004;191(4):1393-7.

[21] Bevis KS, Biggio JR. Cervical conization and the risk of preterm delivery. Am J Obstet Gynecol 2011;205(1):19-27.

[22] Jakobsson M, Gissler M, Paavonen J, Tapper AM. Long-term mortality in women treated for cervical intraepithelial neoplasia. BJOG 2009;116(6):838-44.

[23] Castanon A, Brocklehurst P, Evans H, Peebles D, Singh N, Walker P, et al. Risk of preterm birth after treatment for cervical intraepithelial neoplasia among women attending colposcopy in England: retrospective-prospective cohort study. BM] 2012;345:e5174

[24] Romero R. Prevention of spontaneous preterm birth: the role of sonographic cervical length in identifying patients who may benefit from progesterone treatment. Ultrasound Obstet Gynecol 2007:30(5):675-86.

[25] Himes KP, Simhan HN. Time from cervical conization to pregnancy and preterm birth. Obstet Gynecol 2007;109(2 Pt 1):314-9. 